\title{
Leukocyte capture and modulation of cell-mediated immunity during human sepsis: an ex vivo study
}

Thomas Rimmelé ${ }^{1}$, Ata Murat Kaynar', Joseph N McLaughlin', Jeffery V Bishop ${ }^{1}$, Morgan V Fedorchak², Anan Chuasuwan ${ }^{1}$, Zhiyong Peng ${ }^{1}$, Kai Singbartl', Daniel R Frederick', Lin Zhu', Melinda Carter ${ }^{1}$, William J Federspiel ${ }^{1,2}$, Adriana Zeevi ${ }^{3}$ and John A Kellum ${ }^{1,2^{*}}$

\begin{abstract}
Introduction: Promising preclinical results have been obtained with blood purification therapies as adjuvant treatment for sepsis. However, the mechanisms by which these therapies exert beneficial effects remain unclear. Some investigators have suggested that removal of activated leukocytes from the circulation might help ameliorate remote organ injury. We designed an extracorporeal hemoadsorption device capable of capturing both cytokines and leukocytes in order to test the hypothesis that leukocyte capture would alter circulating cytokine profiles and influence immunological cell-cell interactions in whole blood taken from patients with sepsis.

Methods: We performed a series of ex vivo studies in 21 patients with septic shock and 12 healthy volunteers. Blood circulated for four hours in closed loops with four specially designed miniaturized extracorporeal blood purification devices including two different hemoadsorption devices and a hemofilter in order to characterize leukocyte capture and to assess the effects of leukocyte removal on inflammation and immune function.

Results: Hemoadsorption was selective for removal of activated neutrophils and monocytes. Capture of these cells led to local release of certain cytokines, especially IL-8, and resulted in complex cell-cell interactions involved in cellmediated immunity. Inhibition of cell adherence reversed the cytokine release and the effects on lymphocyte function.

Conclusions: Monocyte and neutrophil capture using a sorbent polymer results in upregulation of IL-8 and modulation of cell-mediated immunity. Further studies are needed to understand better these cellular interactions in order to help design better blood purification therapies.
\end{abstract}

\section{Introduction}

Sepsis is the most common cause of death in the intensive care unit [1]. Care is mostly supportive as specific treatments for sepsis have failed to become universally accepted [2-5]. Blood purification techniques, including high-volume hemofiltration (HVHF), cascade hemofiltration, hemoadsorption, plasmapheresis, coupled plasma filtration adsorption (CPFA), high-adsorption hemofiltration, and high cut-off hemodialysis/hemofiltration, represent a class of therapies for sepsis that have seen promising pre-clinical

\footnotetext{
* Correspondence: Kellumja@upmc.edu

'The CRISMA (Clinical Research, Investigation, and Systems Modeling of Acute Illness) Center, Department of Critical Care Medicine, University of Pittsburgh, School of Medicine, 3550 Terrace Street, Pittsburgh, PA 15261, USA

Full list of author information is available at the end of the article
}

and early clinical results but have not yet been translated into routine clinical practice [6-12].

There are several explanations for the lack of translation of experimental findings from blood purification studies into clinical practice. First, there are no large multicenter trials evaluating the ability of blood purification therapies to improve patient-centered outcomes in sepsis. Second, the non-specific nature of these therapies in removing inflammatory mediators has raised the concern that small beneficial molecules (for example, antibiotics, nutrients, vitamins, trace elements) may also be removed [13-15]. Third, the mechanisms by which these therapies exert beneficial effects remain poorly understood and controversial [16].

\section{Biomed Central}


Recent evidence suggests that these therapies may not only remove soluble mediators of inflammation but may also work at the cellular level, modulating immune function by interacting directly or indirectly with inflammatory cells [12,17-20]. Furthermore, adsorptive materials such as polymyxin B not only adsorb inflammatory mediators and toxins but also remove leukocytes due to cell adsorption onto the surface of the blood purification device [21-24]. Some investigators have suggested that removal of activated leukocytes from the circulation could ameliorate remote organ injury [22,23,25]. Apheresis systems have even been developed with the purpose of leukocyte capture in the setting of acute kidney injury, chronic kidney disease and other refractory inflammatory diseases (for example, ulcerative colitis) [25-29].

As part of an ongoing project to develop a blood purification device for the treatment of sepsis, we designed an extracorporeal hemoadsorption device capable of capturing not only cytokines but also leukocytes. We hypothesized that leukocyte capture would alter the immune response to sepsis. To address this, we performed a series of ex vivo studies with the aim of characterizing leukocyte capture using different extracorporeal blood purification devices. Two different hemoadsorption devices using sorbent polymer were tested, along with a hemofilter used as a control, and the effects of these interactions on inflammation and immune function were characterized in the setting of human sepsis.

\section{Materials and methods Overview}

We obtained blood from both patients with septic shock and healthy volunteers and circulated it for four hours in a closed loop with one of four specially designed miniaturized extracorporeal devices. At baseline and at the end of the session, we measured white blood cell and differential counts, plasma concentrations of various inflammatory mediators, leukocyte cell surface molecule expression and lymphocyte function.

\section{Subjects}

The study was approved by the University of Pittsburgh Institutional Review Board. After consent was obtained, blood was withdrawn from 21 patients with septic shock and from 12 healthy volunteers. Septic shock was defined according to the American College of Chest Physicians/Society of Critical Care Medicine consensus conference criteria [30]. Patients were excluded if pregnant, younger than 18 years, receiving renal replacement therapy, receiving immunosuppressive therapy or if they had a history of hematological malignancy. Healthy volunteers were older than 18 years of age and not pregnant.

\section{Ex vivo circuits and blood purification devices}

Blood was collected into standard vacuum-collection tubes. The experiments consisted of perfusing blood through four different closed miniaturized ex vivo extracorporeal circuits over a period of four hours: 1) a hemoadsorption device containing $1.5 \mathrm{~g}$ of large (approximately 550 to $600 \mu \mathrm{m}$ diameter) polystyrene divinylbenzene copolymer beads (Cytosorb ${ }^{\mathrm{TM}}$; CytoSorbents Corporation, Monmouth Junction, NJ, USA); 2) a hemoadsorption circuit containing $2.5 \mathrm{~g}$ of small (70 to $75 \mu \mathrm{m}$ diameter) Cytosorb beads; 3 ) a hemofiltration circuit with a mini hemofiltration device (Oxiris ${ }^{\circledR}$, Gambro-Hospal, Meyzieu, France); and 4) a sham circuit consisting of the extracorporeal circuit with no blood purification device (that is, a tubing circuit with just an empty cartridge) (Figure 1).

Components of the extracorporeal circuits were polyethylene tubing, a $15 \mathrm{ml}$ blood reservoir (Origen ${ }^{\mathrm{TM}}$, Austin, TX, USA), silicone tubing and a peristaltic pump (Control Company, Friendswood, TX, USA) set up with a blood flow rate of $0.75 \mathrm{ml} /$ minute. For the hemofiltration circuit, saline was used for replacement fluid. The ultrafiltration flow rate and the replacement fluid flow rate were both $0.15 \mathrm{ml} /$ minute, maintaining the total blood volume consistently stable at $15 \mathrm{ml}$. This polyacrilonitrile mini-hemofilter had a surface area of $420 \mathrm{~cm}^{2}$ and was specifically designed and miniaturized for this study. The surface polarity of this blood purification membrane was modified by the addition of a polyethyleneimine coating, a positively-charged polymer, allowing the membrane to catch negatively charged endotoxins via surface adsorption. For the hemoadsorption circuits, the beads were located inside miniaturized cartridges. The difference in diameter between large and small beads resulted in a significant increase of the contact area with blood, from $45 \mathrm{~cm}^{2}$ (large beads) to $297 \mathrm{~cm}^{2}$ (small beads). In all circuits, unfractionated heparin was added to the blood before the beginning of each experiment in order to obtain a heparin concentration of $10 \mathrm{IU} / \mathrm{ml}$. Information regarding the miniaturized hemofiltration and hemoadsorption devices is summarized in Table 1.

\section{Electron microscopy and immunofluorescence images}

We studied the cell adherence to the hemoadsorption beads using scanning electron microscopy (SEM) and characterized adherent cells using immunofluorescence (IF) microscopy.

\section{SEM}

Following the experimental period, beads were removed from the cartridges and fixed in 1\% OsO4. Specimens dehydrated in alcohol gradients were then imaged using JEOL 9335 SEM. 


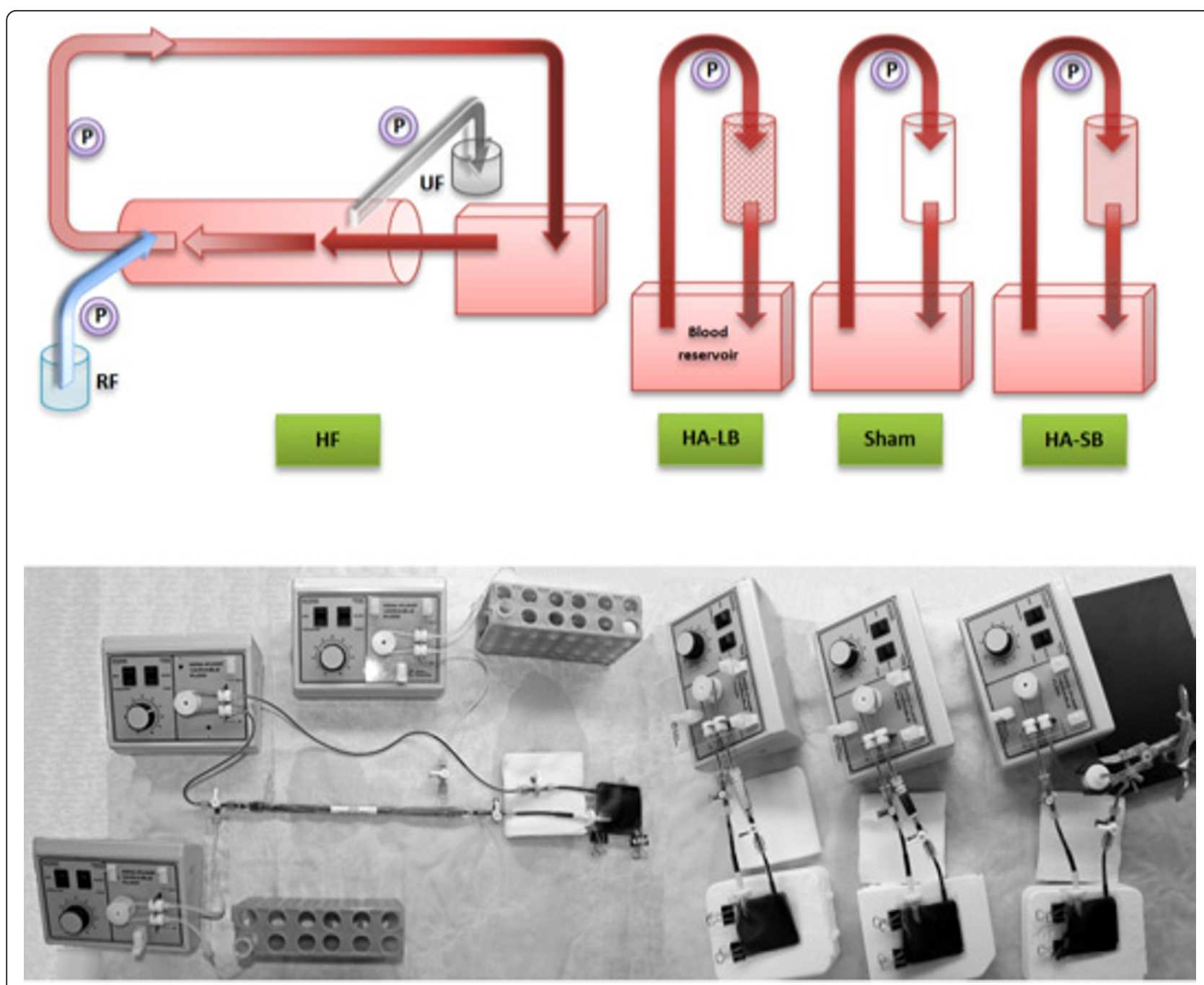

Figure 1 The four ex vivo miniaturized extracorporeal circuits (hemofiltration, hemadsorption with large beads, hemoadsorption with small beads and sham). Blood was circulated through these closed circuits for four hours. HA-LB, hemoadsorption with large beads; HA-SB, hemoadsorption with small beads; HF, hemofiltration; P, mini-pump; RF, replacement fluid; UF, ultrafiltrate.

Table 1 Summary of the characteristics of the miniaturized blood purification devices

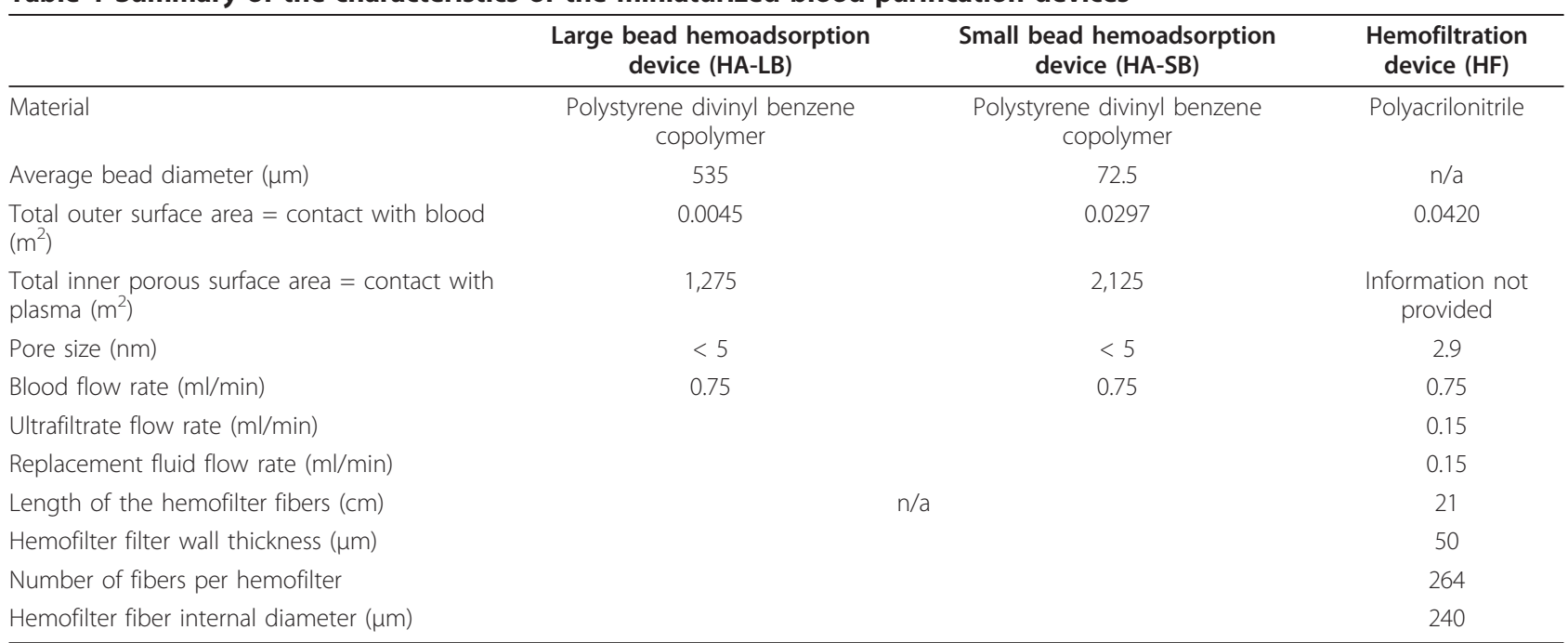


IF

The beads were fixed in $2 \%$ paraformaldehyde, blocked with $2 \%$ bovine serum albumin (BSA) and then incubated with CD14 (Abcam, Cambridge, MA, USA) primary antibody. Fluor-conjugated phalloidin for F-actin and nuclear stain 4',6-diamidino-2-phenylindole (DAPI) were also co-incubated. Beads were then imaged using an Olympus Fluoview confocal microscope.

\section{Cytokine measurements}

Blood samples were withdrawn from the circuits at baseline and after four hours of circulation. Samples were immediately centrifuged at $1,500 \times$ g for 5 minutes at $4{ }^{\circ} \mathrm{C}$ and plasma was removed and stored at $-80^{\circ} \mathrm{C}$ until assayed. Granulocyte macrophage colony-stimulating factor (GM-CSF), tumor necrosis factor (TNF), interferon $\gamma$ and the interleukin (IL) $-1 \beta$, IL-2, IL-4, IL5, IL-6, IL-8, and IL-10 concentrations were measured in duplicate by Luminex ${ }^{\circledR}$ bead technology (Invitrogen, Camarillo, CA, USA).

\section{Leukocyte surface marker expression}

Cell surface markers were measured in monocytes, neutrophils and lymphocytes. Blood samples were withdrawn at baseline and after four hours of circulation through the circuits. Erythrocytes were lysed with BD Pharm Lyse ${ }^{\mathrm{TM}}$ solution (Becton Dickinson, Franklin Lakes, NJ, USA) and washed in 1\% BSA in PBS. Fc receptors were blocked with excess immunoglobulin G (IgG). Cells stained for surface markers were incubated with appropriate antibodies (Becton Dickinson) and fixed in 1\% paraformaldehyde. For nuclear factor kappa B $(\mathrm{NF} \kappa \mathrm{B})$, cells were treated with Cycletest Plus Kit (Becton Dickinson) prior to staining with anti-NF $\kappa \mathrm{B}$ antibody (Santa Cruz Biotechnology Inc, Santa Cruz, CA, USA). Data were acquired on a Beckman Coulter XL-MCL and analyzed with FCS Express (De Novo Software, Los Angeles, CA, USA). Cells were gated by size and granularity for neutrophils and monocytes. $\mathrm{NF} \kappa \mathrm{B}$ cells were gated for positive staining of propidium iodide (PI) and by size. HLA-DR, CD 11b, CD 11a, CD 62L, TNF-alpha converting enzyme (TACE), and NF $\kappa \mathrm{B}$ expression was measured by the geometric mean of fluorescence intensity. Apoptosis was measured as percent positive for Annexin V with PI excluding necrotic cells. T-cells were stained with BD Fast-Immune mix of CD3/ CD4/CD69. T-Lymphocytes were gated on CD3+ and gated into CD4+ and CD4- populations. CD69 was measured as \% positive and as geometric mean of CD3+/CD4 + and CD3+/CD4- cells.

\section{Measurement of lymphocyte function}

We measured intracellular ATP production in CD3+ and CD4+ lymphocytes as a marker of global lymphocyte immune function following phytohemagglutinin
(PHA) and concavalin (Con-A) mitogen stimulation (The Cylex's Immuknow ${ }^{\circledR}$ \& T-Cell Memory ${ }^{\mathrm{TM}}$ assays, Cylex Inc., Columbia, MD, USA). Briefly, for both assays, $250 \mu$ l of whole blood was diluted with sample diluent, then added to the appropriate wells of the microtiter plates and incubated for 15 to 18 hours at $37^{\circ} \mathrm{C}$, with and without stimulant (PHA or Con-A). The following day, CD4+ or CD3+ cells were selected within the microwells using magnetic particles coated with anti-human CD4 and CD3 monoclonal antibodies (Dynabeads ${ }^{\circledR}$, Dynal Biotech ASA, Oslo, Norway), washed to remove residual cells and lysed with lysis reagent to release intracellular ATP. ATP was measured using a luciferase-based reaction with a luminometer. Results were expressed as the amount of ATP in nanograms per milliliter of whole blood.

\section{Experiments with ethylenediaminetetraacetic acid}

Blood was withdrawn from seven healthy volunteers and was circulated through the four circuits during four hours. Blood collection tubes containing ethylenediaminetetraacetic acid (EDTA) were used and no additional anticoagulation was added in the circuits after blood draw, leading to an EDTA concentration of $1.8 \mathrm{mg}$ per milliliter of blood. White blood cell and differential counts, cytokine level measurements and lymphocyte function activity were recorded.

\section{Statistical analysis}

Non-normally distributed continuous data were expressed as the median and interquartile range (IQR). Where indicated, values were normalized to conditions before exposure to the indicated devices and are reported as \% Uncirculated. Comparison of group differences for continuous variables was done by the non parametric Mann-Whitney test. Statistical tests were performed using the Sham group as the reference. A statistical and graphing software program (GraphPad Prism, version 5, GraphPad Software, La Jolla, CA) was used for data processing and analysis. All $P$ values were two-sided and statistical significance was set at an $\alpha$-value of 0.05 .

\section{Results}

\section{Hemoadsorption devices were selective for removal of} neutophils and monocytes

Blood circulation through all four circuits resulted in the removal of leukocytes and platelets, both from septic and healthy blood (Figure 2). This was particularly significant for hemoadsorption, especially with the small beads, where less than $10 \%$ of platelets and leukocytes remained circulating at the end of the experiments with septic blood. Importantly, the leukocyte depletion was primarily seen in monocytes and neutrophils whereas lymphocytes showed little affect. The circuit without a 


\section{Septic}

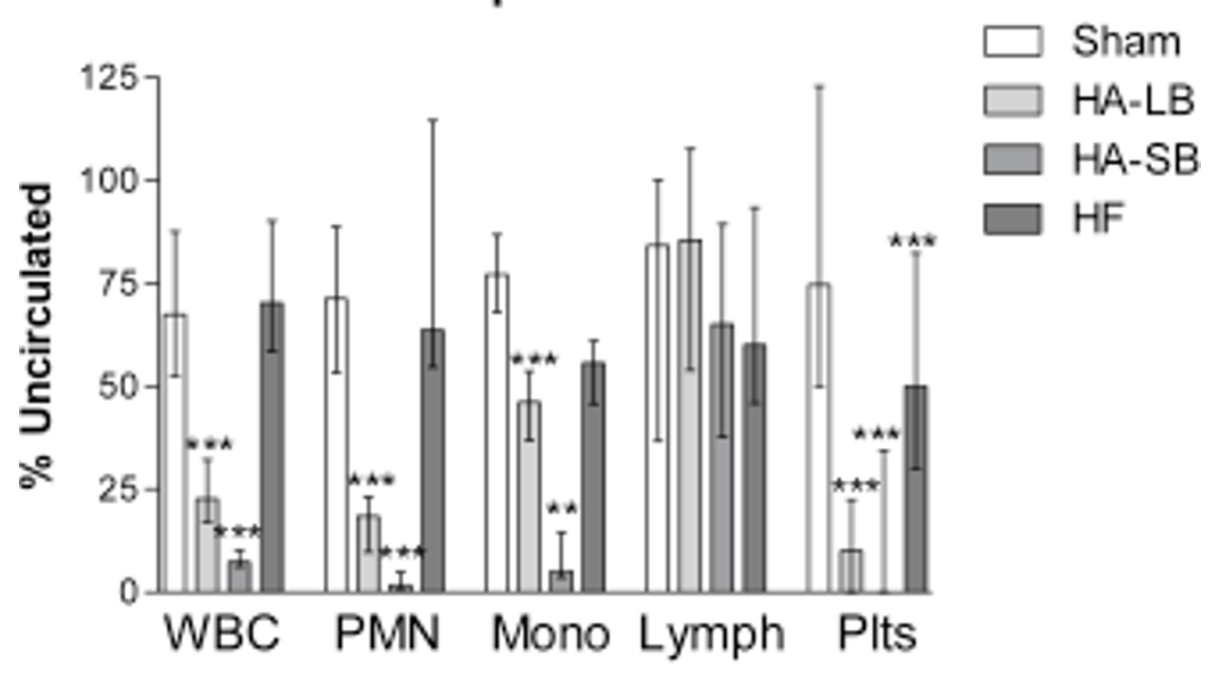

\section{Healthy}

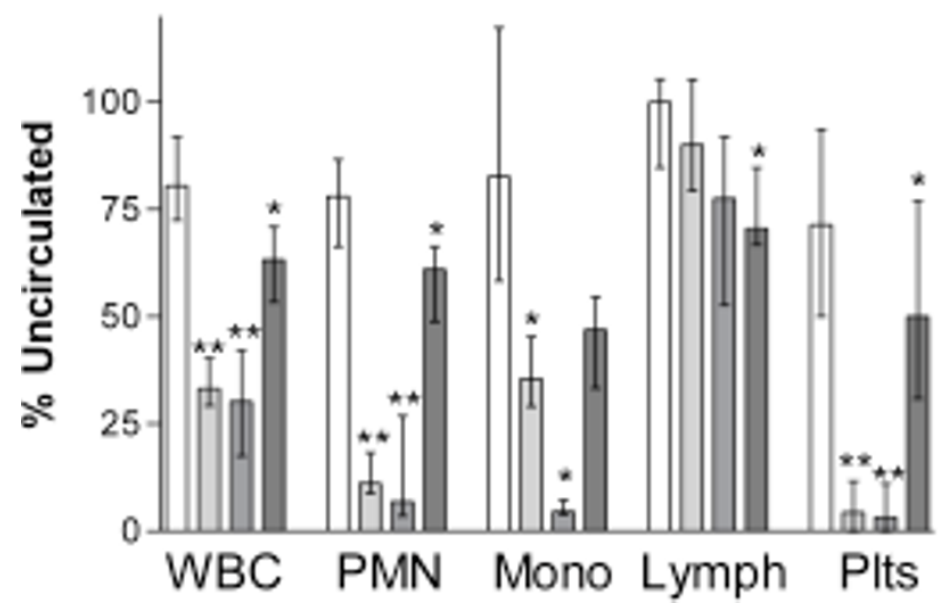

Figure 2 Effects of extracorporeal circuits on white blood cells (WBC), neutrophils (PMN), monocytes (Mono), lymphocytes (Lymph) and platelets (PIts). Results are expressed as \% of cells present before circulation through the circuits (uncirculated condition), in blood obtained from septic patients and healthy volunteers (medians with interquartile ranges). ${ }^{*} P<.05,{ }^{* *} P<.01,{ }^{* * *} P<.001$ compared with Sham.

blood purification device (sham circuit) was responsible for a slight decrease in leukocytes and platelets. EM and IF images confirmed adsorption of leukocytes and platelets onto the surface of the beads (Figure 3).

\section{Hemoadsorption resulted in depletion of CD11b positive} cells and led to release of IL-8 and TNF

Compared to baseline, hemofiltration and hemoadsorption decreased the concentration of IL-6 and IL-10 in septic blood (Figure 4). As expected, cytokine levels in healthy volunteers were very low. A significant production of IL-8 and TNF occurred with the large bead hemoadsorption device; levels increased in both septic and healthy blood. Although changes in TNF were statistically significant, levels were quite low, especially in septic blood $(<10 \mathrm{pg} / \mathrm{ml})$. However, IL-8 levels increased dramatically, exceeding $1,000 \mathrm{pg} / \mathrm{ml}$ in both septic and healthy blood. IFN- $\gamma$, IL-2, IL-4 and IL-5 levels did not change after circulation through the devices. Neutrophils and monocytes remaining in circulation at the end of the 


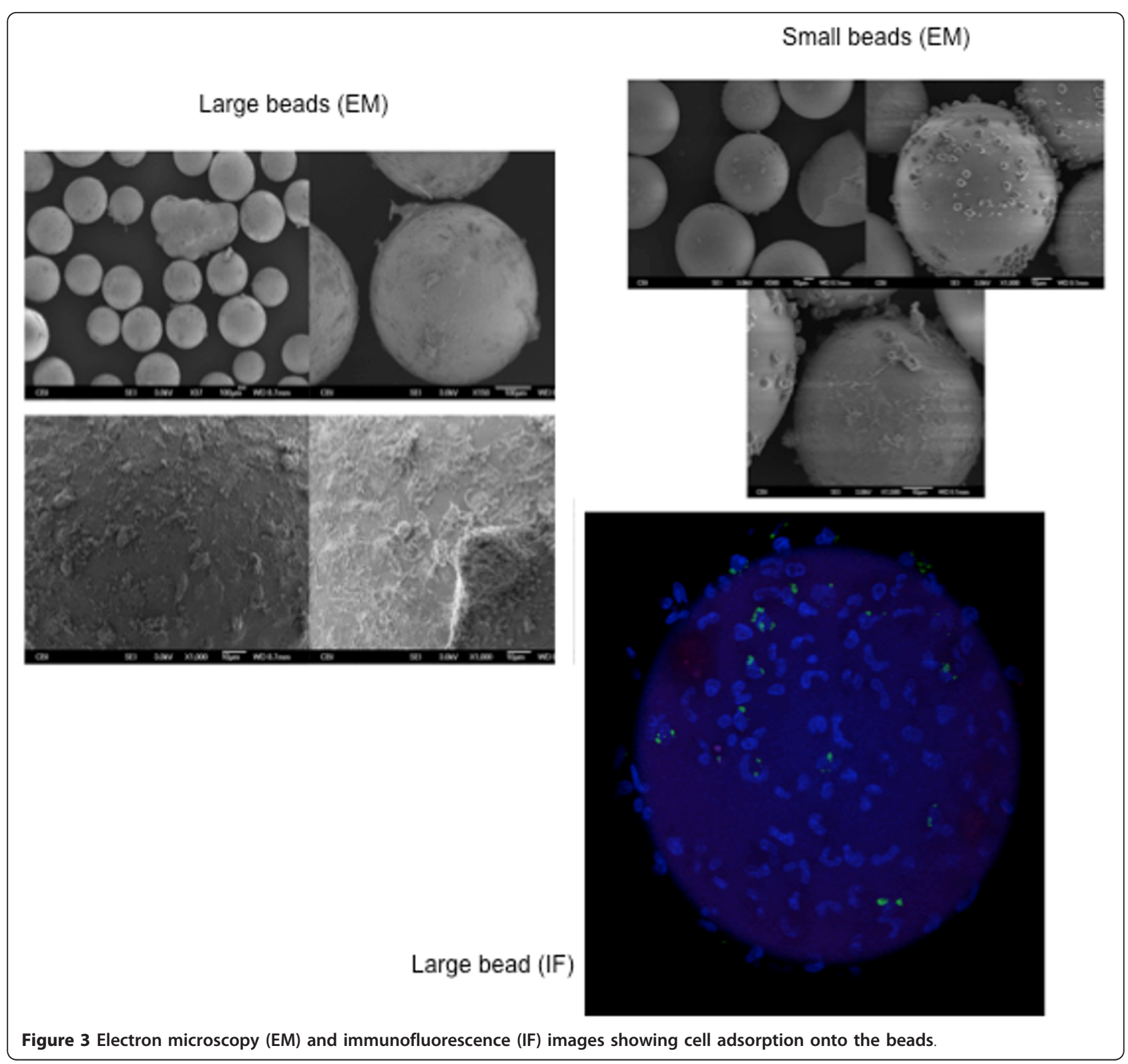

experiment with hemoadsorption were less likely to express CD11b (Figure 5). By contrast, molecules expressed on the surface of lymphocytes were not changed after blood purification using the different devices.

\section{Monocyte depletion leads to modulation of lymphocyte function}

Although lymphocytes were not captured by the devices, $\mathrm{T}$ cell activity (both $\mathrm{CD} 3+$ and $\mathrm{CD} 4+$ ) was decreased with hemoadsorption, both in septic and healthy blood (Figure 6). In septic blood, the Immuknow value with PHA stimulation decreased from 361 (53 to 462) to 72 (3 to 219), $P=0.0464$ (large beads), and to 9 (2 to 13), $P=0.0048$ (small beads). Similar results were seen with
Con A stimulation: 154 (17 to 394$)$ to 40 (15 to 69 ), $P=$ 0.0071 (large beads) and to 1 (0.3 to 3 ) $P=0.0007$ (small beads). By contrast, there was no significant change of the Immuknow value when blood was circulated through the sham and the hemofiltration circuits.

EDTA blocked cell capture, ameliorated IL-8 release and reversed T-cell suppression

In order to determine if the effects on cytokines and T-cells were mediated by capture of neutrophils and/or monocytes, we circulated healthy blood through the circuits after anticoagulation with increased concentrations of heparin, citrate and EDTA. In these experiments, there was no change with heparin and citrate (data not 


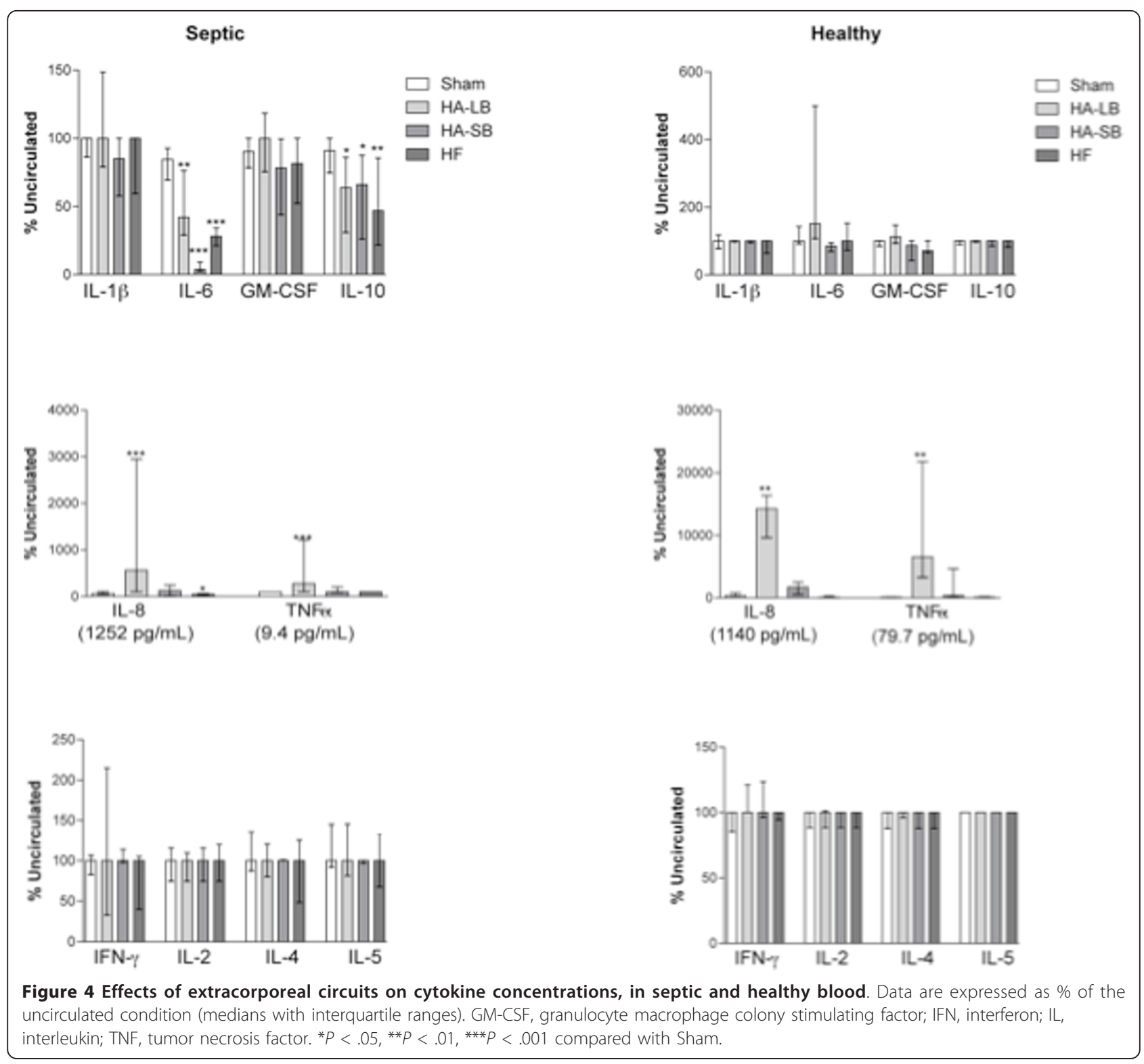

shown). However, EDTA blocked leukocyte and platelet capture (Figure 7) leading to markedly attenuated IL-8 release (reaching only $67 \mathrm{pg} / \mathrm{ml}$ with the large bead device). Immuknow values remained similar with hemoadsorption as compared to the baseline value. Of note, the Immuknow is affected by EDTA since the PHA results before circulation through the circuits are already reduced (see comparison with Figure 6). Con A is suppressed completely and cannot be evaluated (data not shown).

\section{Discussion}

In this ex vivo study using human whole blood taken from patients with sepsis and healthy volunteers, we tested the hypothesis that leukocyte capture modulates inflammatory cytokines and immune cell function. We designed a new hemoadsorption device, capable of capturing not only inflammatory mediators but also activated leukocytes, and we examined the effects of this therapy on inflammation and immune function. Our results showed that while monocytes and neutrophils (along with platelets) were captured by the hemoadsorption device, lymphocytes were not affected. Furthermore, capture was preferential to activated cells as evidenced by the marked reduction in $\mathrm{CD} 11 \mathrm{~b}+$ and less dramatic reduction in CD11a+ cells remaining in circulation after treatment. Importantly, capture of monocytes and neutrophils led to local release of certain cytokines, especially IL-8, and resulted in changes in $\mathrm{T}$-cell function as measured by response to stimulation with PHA and Con A. Inhibition of monocyte and 


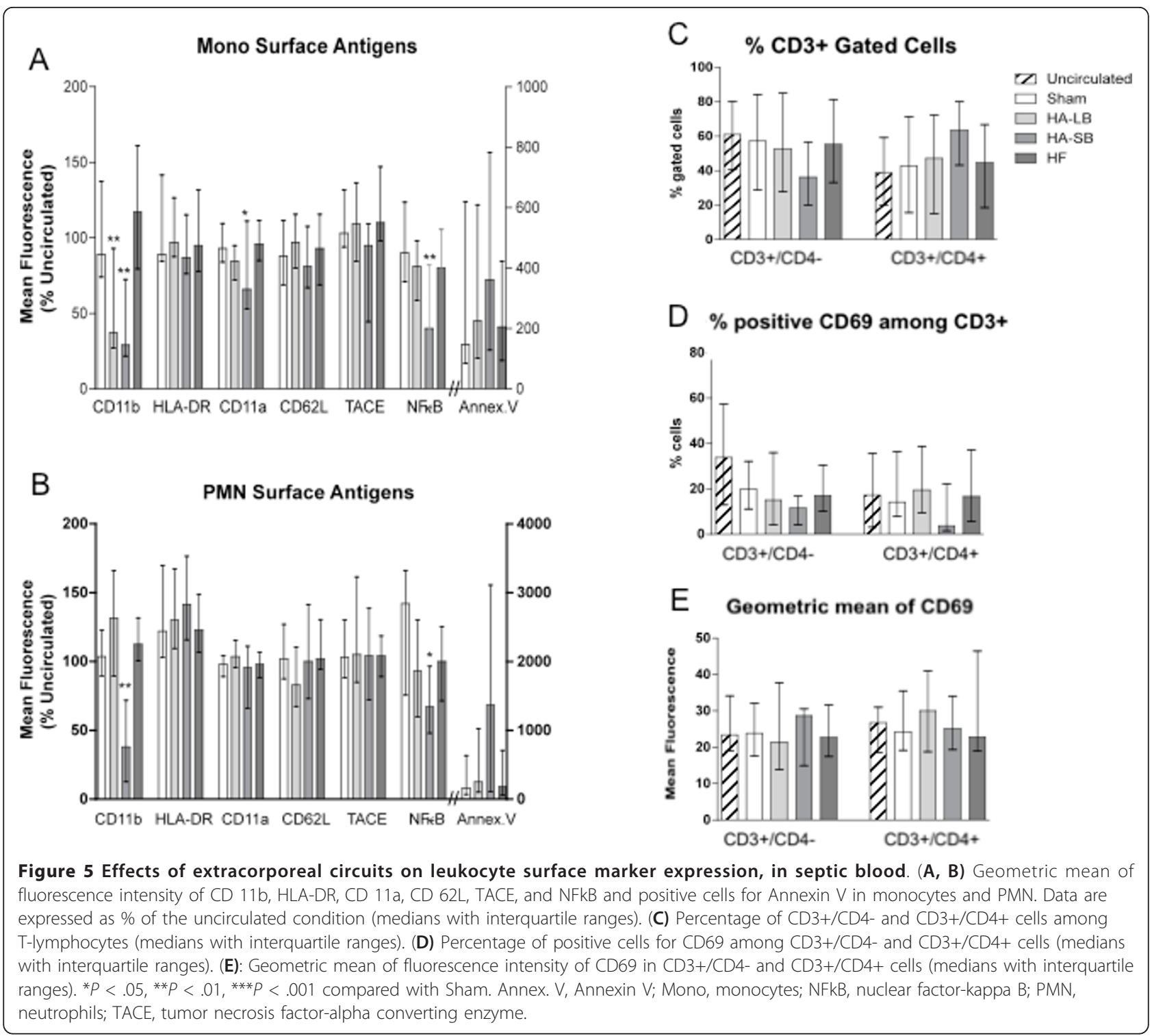

neutrophil capture with EDTA nearly abolished IL-8 release and reversed the $\mathrm{T}$ cell suppression.

Numerous experimental and clinical studies have reported that various forms of extracorporeal blood purification used in sepsis are effective in clearing inflammatory mediators and endotoxins from the plasma and are responsible for an improvement of physiological parameters (for example, hemodynamics, oxygenation) $[7,8,10,17,31]$. Cruz et al. recently showed reduced mortality when hemoadsorption was used in patients with abdominal sepsis [2]. However, the mechanisms by which these therapies exert beneficial effects are not entirely understood [16]. Recent evidence suggests that these blood purification therapies may not only remove soluble mediators of inflammation but may also work at the cellular level, modulating the immune function by interacting directly or indirectly with inflammatory cells [12,17-20]. Moreover, it has recently been shown that polymyxin B hemoadsorption does more than adsorb inflammatory mediators and toxins- it also removes leukocytes via cell adsorption onto the surface of the device [21-23]. Kumagai et al. found very similar results to ours with a significant decrease of neutrophils, monocytes and lymphocytes after ex vivo polymyxin B hemoadsorption $(78 \%, 70 \%$ and $10 \%$, respectively, compared with baseline values). Additionally, this study also suggested that the adhesion of leukocytes preferentially affected activated neutrophils, therefore resulting in a decreased ability for the remaining circulating cells to cause endothelial damage [22]. Similarly, Abe et al. also demonstrated that a large number of cells captured by polymyxin B-immobilized fiber columns were activated neutrophils, highly expressing HLA-DR, CD14, 


\section{Septic}

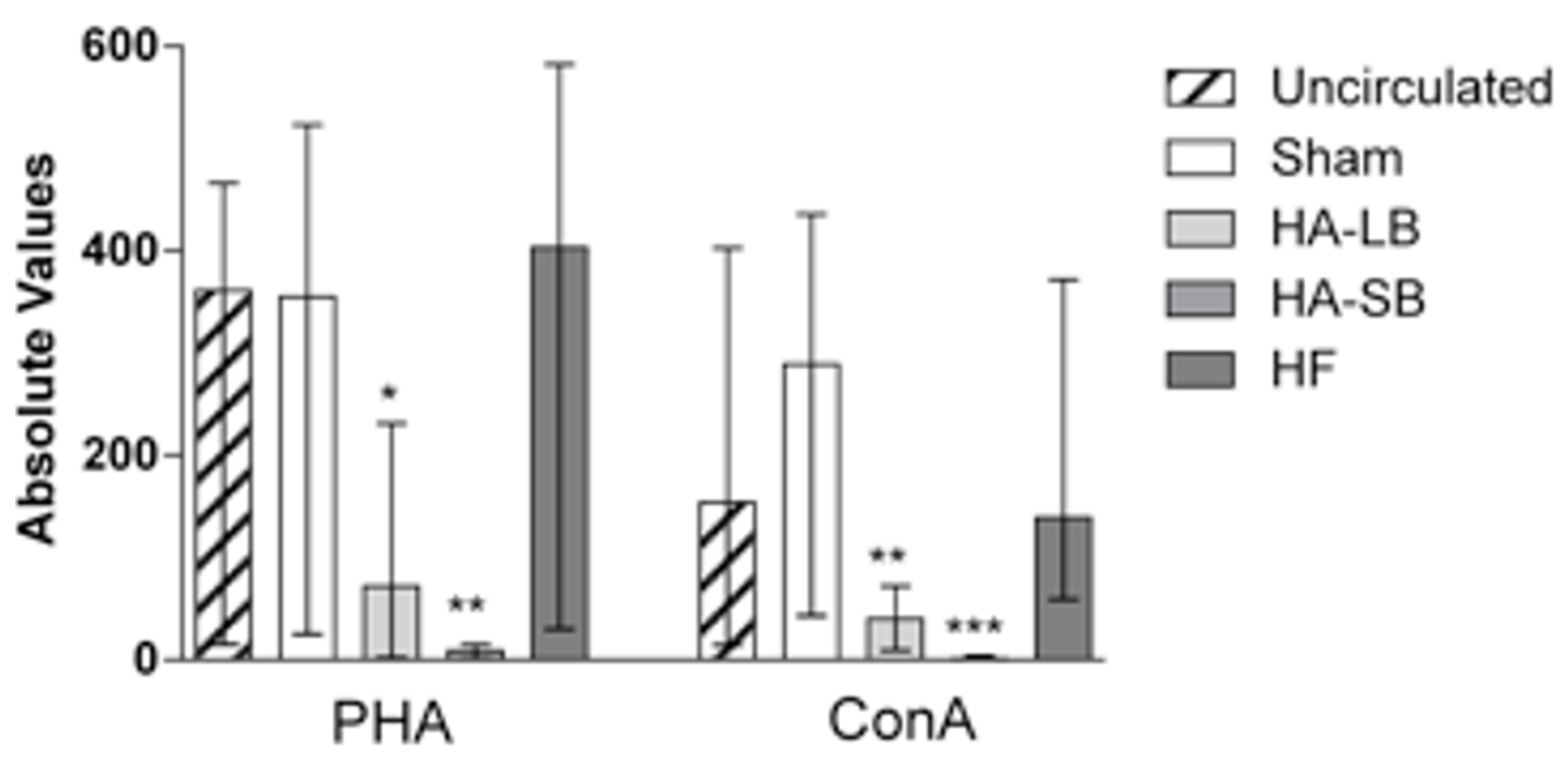

\section{Healthy}

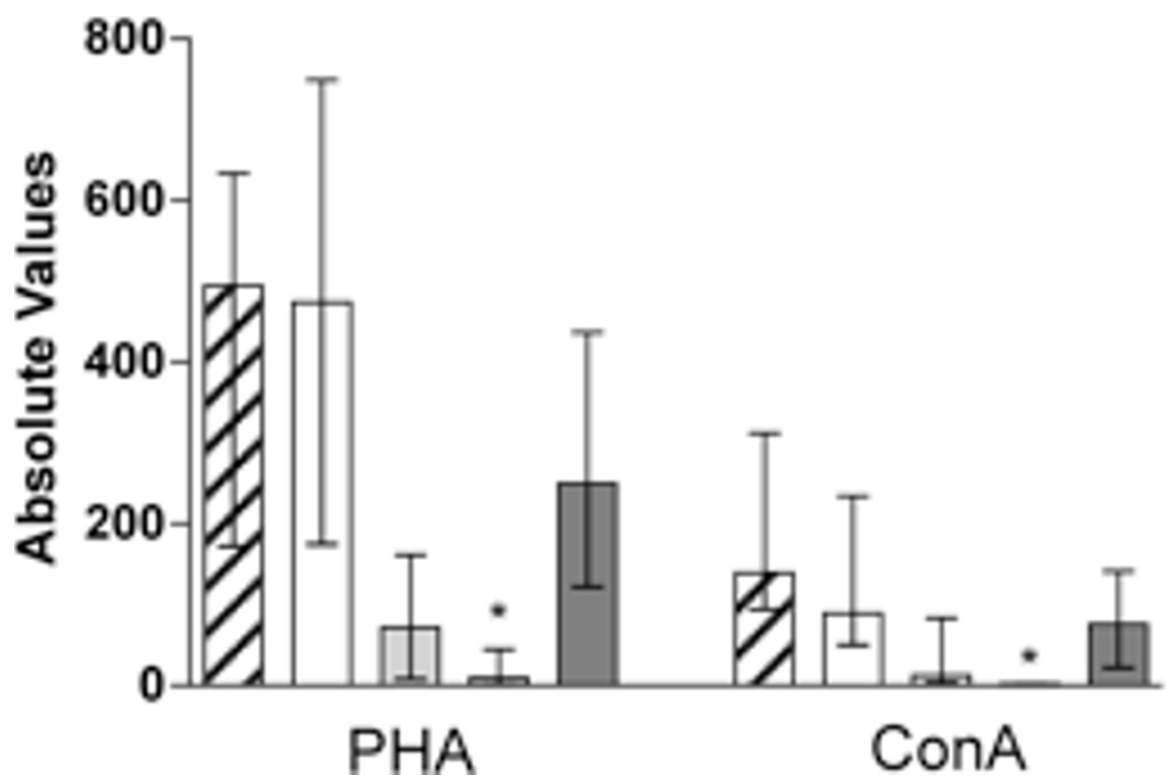

Figure 6 Effects of extracorporeal circuits on Immuknow \& T-Cell Memory assays in septic and healthy blood. Data are expressed as absolute values of the amount of ATP in nanograms per milliliter of whole blood (medians with interquartile ranges). ${ }^{*} P<.05$, ${ }^{* *} P<.01$, ${ }^{* * *} P<$ .001 compared with Sham. Con-A, concavalin A; PHA, phytohemagglutinin.

CD62L and CD114 [21]. Finally, another recent report from Nishibori et al. also suggested that a polymyxin Bimmobilized fiber column specifically removed monocytes that had been activated during septic shock [23].
In our study, when blood was exposed to the hemoadsorption device, we observed that circulating platelet, monocyte and neutrophil counts decreased due to their adsorption onto the beads (Figures 2 and 3). Leukocyte 


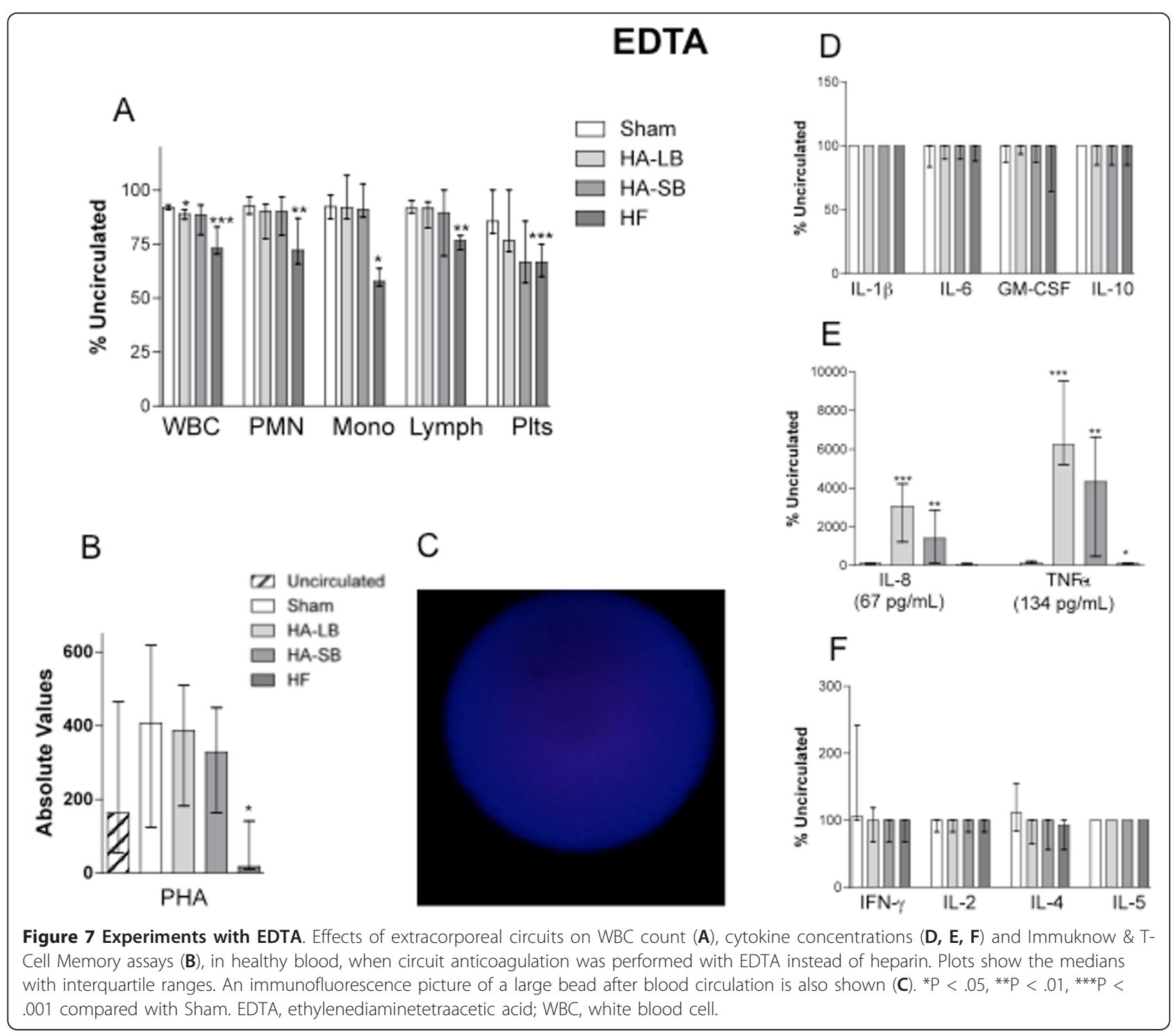

and platelet counts were both significantly reduced with hemoadsorption compared to sham and were even more reduced with the small beads, as compared to the large beads, most likely due to the increased surface area and reduced interstitial space between beads in the device. Moreover, it seems likely that adsorption of platelets, neutrophils and monocytes occurred in an inter-related way $[32,33]$. Indeed, it is known that platelets are readily activated by shear force and contact with biomaterials [34]. This activation, in turn, leads to changes in the surface expression of integrins and adhesion molecules, leading to platelet aggregation and deposition on biomaterials. Platelet activation also leads to release of cytokines, thereby providing both the chemical signal and appropriate surface for leukocyte activation and adhesion $[35,36]$.

Importantly, we also found that captured leukocytes released low levels of TNF and very high levels of IL-8.
IL-8, a chemokine, is mainly produced by activated monocytes and functions to recruit neutrophils (IL-8 is also known as neutrophil chemotactic factor) [37]. Interestingly, our devices did not capture lymphocytes. Lymphocyte concentrations remained quite stable after circulation through the circuits and this correlates with the absence of production of the lymphokines IL-2, IL-4, IL-5 and IFN $\gamma$ (Figure 4) and the absence of changes in the expression of CD4, CD8 and CD69 on the lymphocyte surface (Figure 5).

We evaluated T-lymphocyte function with the Immuknow test. This assay is approved for monitoring immune cell function in immunosuppressed populations [38]. Immune cell function is considered low when values of this assay are below $225 \mathrm{ng} / \mathrm{ml}$, medium when 225 to $525 \mathrm{ng} / \mathrm{ml}$ and high (normal) when more than $525 \mathrm{ng} / \mathrm{ml}$ [39]. T-cell function was much more affected with small 
bead hemoadsorption rather than with large beads. Indeed, after four hours of circulation in the small bead circuits, lymphocytes were unresponsive (Figure 6). Furthermore, our findings support the conclusion that lymphocyte function was not altered because of a decrease in the number of lymphocytes or lymphocyte subtypes (Figures 2 and 5). Since the activation of $\mathrm{T}$ cells needs to occur in the presence of antigen presenting cells, the removal of monocytes that function as antigen presenting cells in this in vitro system most likely explains the absence of response from the T-cells. This was confirmed by the EDTA experiments that abolished cell capture and completely reversed the inhibition of lymphocyte activation.

Our study has some limitations. First, as an ex vivo investigation, we cannot determine the clinical effects of the changes in cell numbers and function we observed. Our closed loop experimental design using fresh whole blood ex vivo is not comparable to that seen in vivo. Indeed, ex vivo circuits work as a single compartment model, whereas the in vivo use of a hemoadsorption cartridge integrates into a multi-compartment state where activated cells move into tissues or adhere to vessel walls and are then not available for capture by the device. Moreover, as compared to the total blood volume of the ex vivo circuit, the surface area of the hemofiltration membrane was proportionally larger than what it could be in a human in vivo condition. The effects of the devices could, therefore, have been magnified. Second, our results on leukocyte surface marker expression reflect only the remaining circulating cells not those adsorbed onto the beads. Indeed, we could not study the adherent cells directly and can, therefore, only infer what their surface marker expression profile was like. Moreover, we are unable to answer the question whether or not the cell adsorption was a transient or a definitive phenomenon. Third, the relatively low Immuknow absolute values observed in all groups during the EDTA experiments (particularly with Con A), as compared with heparin or citrate anticoagulation, may most likely be explained by the metal ion chelating properties of EDTA, affecting peripheral blood mononuclear cell proliferation and stimulation [40]. Indeed, we were surprised to observe no change in cell capture with heparin or citrate despite some evidence that these agents have differing effects when used for anticoagulation of extracorporeal devices in models of sepsis [41].

These limitations aside, this study supports the novel concept that capture of activated leukocytes from the circulation can be achieved by hemoadsorption. Such therapy could be beneficial by removing activated cells that have deleterious effects, such as disruption of endothelial integrity and impairment of microcirculation by overproduction of proteases and oxygen radicals [22,42-44]. This approach is already used as a therapeutic strategy for other inflammatory diseases. Indeed, some extracorporeal apheresis systems (for example, cellulose acetate beads) have been developed to remove activated monocytes and granulocytes in order to treat specific refractory and inflammatory diseases associated with leukocytes such as ulcerative colitis, neutrophilic dermatosis and psoriatic arthritis [27-29]. More recently, Humes et al. have also developed a selective cytopheretic inhibitory synthetic membrane to treat the immunological dysregulation of acute kidney injury and chronic kidney disease, binding and inhibiting circulating activated leukocytes along a continuous renal replacement extracorporeal circuit $[26,45]$.

\section{Conclusions}

In summary, our study shows that capture of activated monocytes and neutrophils by hemoadsorption interferes with the immune response, modulating $\mathrm{T}$-cell function. These findings lead us to propose a new mechanism for how blood purification therapies may modulate the immune response in patients with sepsis. Additional studies are needed to further investigate this concept.

\section{Key messages}

- Leukocyte capture using a hemoadsorption device modulates cell-mediated immunity.

- Removal of activated leukocytes may offer great potential as an adjunct treatment for sepsis and may help explain some of the beneficial effects of existing blood purification therapies.

- Further knowledge of the complex cell-cell interactions that occur inside a leukocyte capture device is needed in order to develop this technology.

\section{Abbreviations}

BSA: bovine serum albumin; Con-A: concavalin-A; CPFA: coupled plasma filtration adsorption; EDTA: ethylenediaminetetraacetic acid; GM-CSF: granulocyte macrophage colony-stimulating factor; HVHF: high-volume hemofiltration; IF: immunofluorescence; IL: interleukin; IQR: interquartile range; PHA: phytohemagglutinin; PI: propidium iodide; PBS: phosphate buffered saline; SEM: scanning electron microscopy; TNF: tumor necrosis factor.

\section{Authors' contributions}

$T R$, AMK and JAK participated in research design, writing of the manuscript, performance of the research, and data analysis; JB, MF, AC, ZP, KS, DRF, LZ, MC, WJF and AZ participated in performance of the research and data analysis; JNM participated in statistical aspects of data analysis; all authors contributed to the critical review and revision of the manuscript and approved it for publication.

\section{Competing interests}

TR has received consulting fees from Gambro. KS has received speaker honorarium from Cytosorbents. JK has received consulting fees from Cytosorbents, Gambro and Spectral Diagnostics and has also received research grants from Cytosorbents, Gambro, Kaneka, and Spectral Diagnostics. JK has licensed unrelated technologies through the University of Pittsburgh to Cytosorbents and Spectral Diagnostics. None of the other authors report any competing interests. 


\section{Acknowledgements}

The authors would like to thank Kathy Spitchy, Kathryn Arbogast, Gambro and CytoSorbents for their technical assistance. This work was supported by Award Numbers R01HL080926 and K08HL086671 from the National Heart, Lung, and Blood Institute (NHLBI). The content is solely the responsibility of the authors and does not necessarily represent the official views of the NHLBI or the National Institutes of Health.

\section{Author details}

'The CRISMA (Clinical Research, Investigation, and Systems Modeling of Acute IIIness) Center, Department of Critical Care Medicine, University of Pittsburgh, School of Medicine, 3550 Terrace Street, Pittsburgh, PA 15261, USA. ${ }^{2}$ McGowan Institute for Regenerative Medicine, University of Pittsburgh, 450 Technology Drive, Pittsburgh, PA 15219, USA. ${ }^{3}$ The Thomas E. Starzl Transplantation Institute, University of Pittsburgh, 200 Lothrop Street, Pittsburgh, PA 15261, USA.

Received: 11 November 2012 Revised: 17 February 2013

Accepted: 18 March 2013 Published: 26 March 2013

\section{References}

1. Angus DC, Linde-Zwirble WT, Lidicker J, Clermont G, Carcillo J, Pinsky MR: Epidemiology of severe sepsis in the United States: analysis of incidence, outcome, and associated costs of care. Crit Care Med 2001, 29:1303-1310.

2. Cruz DN, Antonelli M, Fumagalli R, Foltran F, Brienza N, Donati A, Malcangi V, Petrini F, Volta G, Bobbio Pallavicini FM, Rottoli F, Giunta F, Ronco C: Early use of polymyxin B hemoperfusion in abdominal septic shock: the EUPHAS randomized controlled trial. JAMA 2009, 301:2445-2452.

3. Kellum JA, Uchino S: International differences in the treatment of sepsis: are they justified? JAMA 2009, 301:2496-2497.

4. Lindenauer PK, Rothberg MB, Nathanson BH, Pekow PS, Steingrub JS: Activated protein $\mathrm{C}$ and hospital mortality in septic shock: a propensitymatched analysis. Crit Care Med 2010, 38:1101-1107.

5. Kalil AC: Does recombinant activated protein C work in patients with severe sepsis? Crit Care Med 2010, 38:1217-1220.

6. Busund R, Koukline V, Utrobin U, Nedashkovsky E: Plasmapheresis in severe sepsis and septic shock: a prospective, randomised, controlled trial. Intensive Care Med 2002, 28:1434-1439.

7. Honore PM, Jamez J, Wauthier M, Lee PA, Dugernier T, Pirenne B, Hanique G, Matson JR: Prospective evaluation of short-term, high-volume isovolemic hemofiltration on the hemodynamic course and outcome in patients with intractable circulatory failure resulting from septic shock. Crit Care Med 2000, 28:3581-3587.

8. Morgera S, Haase M, Kuss T, Vargas-Hein O, Zuckermann-Becker H, Melzer C, Krieg H, Wegner B, Bellomo R, Neumayer HH: Pilot study on the effects of high cutoff hemofiltration on the need for norepinephrine in septic patients with acute renal failure. Crit Care Med 2006, 34:2099-2104.

9. Peng ZY, Carter MJ, Kellum JA: Effects of hemoadsorption on cytokine removal and short-term survival in septic rats. Crit Care Med 2008, 36:1573-1577.

10. Rimmelé T, Assadi A, Cattenoz M, Desebbe O, Lambert C, Boselli E, Goudable J, Etienne J, Chassard D, Bricca G, Allaouchiche B: High-volume haemofiltration with a new haemofiltration membrane having enhanced adsorption properties in septic pigs. Nephrol Dial Transplant 2009, 24:421-427.

11. Rimmelé T, Wey PF, Bernard N, Monchi M, Semenzato N, Benatir F, Boselli E, Etienne J, Goudable J, Chassard D, Bricca G, Allaouchiche B: Hemofiltration with the Cascade system in an experimental porcine model of septic shock. Ther Apher Dial 2009, 13:63-70.

12. Ronco C, Brendolan A, Lonnemann G, Bellomo R, Piccinni P, Digito A, Dan M, Irone M, La Greca G, Inguaggiato P, Maggiore U, De Nitti C, Wratten ML, Ricci Z, Tetta C: A pilot study of coupled plasma filtration with adsorption in septic shock. Crit Care Med 2002, 30:1250-1255.

13. Maxvold NJ, Smoyer WE, Custer JR, Bunchman TE: Amino acid loss and nitrogen balance in critically ill children with acute renal failure: a prospective comparison between classic hemofiltration and hemofiltration with dialysis. Crit Care Med 2000, 28:1161-1165.

14. Deshpande P, Chen J, Gofran A, Murea M, Golestaneh L: Meropenem removal in critically ill patients undergoing sustained low-efficiency dialysis (SLED). Nephrol Dial Transplant 2010, 25:2632-2636.
15. Bouman CS: Antimicrobial dosing strategies in critically ill patients with acute kidney injury and high-dose continuous veno-venous hemofiltration. Curr Opin Crit Care 2008, 14:654-659.

16. Rimmelé T, Kellum JA: Clinical review: blood purification for sepsis. Crit Care 2011, 15:205.

17. Kellum JA, Song $M$, Venkataraman R: Hemoadsorption removes tumor necrosis factor, interleukin-6, and interleukin-10, reduces nuclear factorkappaB DNA binding, and improves short-term survival in lethal endotoxemia. Crit Care Med 2004, 32:801-805.

18. Morgera S, Haase M, Rocktäschel J, Böhler T, Vargas-Hein O, Melzer C, Krausch D, Kox WJ, Baumann G, Beck W, Göhl H, Neumayer HH: Intermittent high-permeability hemofiltration modulates inflammatory response in septic patients with multiorgan failure. Nephron Clin Pract 2003, 94:c75-80.

19. Ono S, Tsujimoto H, Matsumoto A, lkuta S, Kinoshita M, Mochizuki H: Modulation of human leukocyte antigen-DR on monocytes and CD16 on granulocytes in patients with septic shock using hemoperfusion with polymyxin B-immobilized fiber. Am J Surg 2004, 188:150-156.

20. Peng ZY, Wang HZ, Carter MJ, Dileo MV, Bishop JV, Zhou FH, Wen XY, Rimmelé T, Singbartl K, Federspiel WJ, Clermont G, Kellum JA: Acute removal of common sepsis mediators does not explain the effects of extracorporeal blood purification in experimental sepsis. Kidney Int 2012, 81:363-369.

21. Abe S, Seo Y, Hayashi H, Matsuda K, Usuki J, Azuma A, Kudoh S, Gemma A: Neutrophil adsorption by polymyxin B-immobilized fiber column for acute exacerbation in patients with interstitial pneumonia: a pilot study. Blood Purif 2010, 29:321-326.

22. Kumagai T, Takeyama N, Yabuki T, Harada M, Miki Y, Kanou H, Inoue S, Nakagawa T, Noguchi $\mathrm{H}$ : Apheresis of activated leukocytes with an immobilized polymyxin B filter in patients with septic shock. Shock 2010, 34:461-466.

23. Nishibori M, Takahashi HK, Katayama H, Mori S, Saito S, Iwagaki H, Tanaka N, Morita K, Ohtsuka A: Specific removal of monocytes from peripheral blood of septic patients by polymyxin B-immobilized filter column. Acta Med Okayama 2009, 63:65-69.

24. Novelli G, Ferretti G, Ruberto F, Morabito V, Pugliese F: Early management of endotoxemia using the endotoxin activity assay and polymyxin Bbased hemoperfusion. Contrib Nephrol 2010, 167:91-101.

25. Ding $F$, Song JH, Jung JY, Lou L, Wang $M$, Charles $L$, Westover $A$, Smith PL, Pino CJ, Buffington DA, Humes HD: A biomimetic membrane device that modulates the excessive inflammatory response to sepsis. PLoS One 2011, 6:e18584.

26. Ding F, Yevzlin AS, Xu ZY, Zhou Y, Xie QH, Liu JF, Zheng Y, DaSilva JR, Humes HD: The effects of a novel therapeutic device on acute kidney injury outcomes in the intensive care unit: a pilot study. ASAIO J 2011, 57:426-432.

27. Kanekura T, Hiraishi K, Kawahara K, Maruyama I, Kanzaki T: Granulocyte and monocyte adsorption apheresis (GCAP) for refractory skin diseases caused by activated neutrophils and psoriatic arthritis: evidence that GCAP removes Mac-1-expressing neutrophils. Ther Apher Dial 2006, 10:247-256.

28. Saniabadi AR, Hanai H, Takeuchi K, Umemura K, Nakashima M, Adachi T, Shima C, Bjarnason I, Lofberg R: Adacolumn, an adsorptive carrier based granulocyte and monocyte apheresis device for the treatment of inflammatory and refractory diseases associated with leukocytes. Ther Apher Dial 2003, 7:48-59.

29. Yonemura K, Ohashi N, Kajimura M, Hishida A: Transient leukopenia and anaphylatoxin production during granulocyte apheresis as treatment for ulcerative colitis. J Clin Apher 2002, 17:107-110.

30. Levy MM, Fink MP, Marshall JC, Abraham E, Angus D, Cook D, Cohen J, Opal SM, Vincent JL, Ramsay G, SCCM/ESICM/ACCP/ATS/SIS: 2001 SCCM/ ESICM/ACCP/ATS/SIS International Sepsis Definitions Conference. Crit Care Med 2003, 31:1250-1256.

31. Cole L, Bellomo R, Journois D, Davenport P, Baldwin I, Tipping P: Highvolume haemofiltration in human septic shock. Intensive Care Med 2001, 27:978-986.

32. Ploppa A, Schmidt V, Hientz A, Reutershan J, Haeberle HA, Nohé B: Mechanisms of leukocyte distribution during sepsis: an experimental study on the interdependence of cell activation, shear stress and endothelial injury. Crit Care 2010, 14:R201.

33. Neto HA, Kubes P: Platelets, endothelium and shear join forces to mislead neutrophils in sepsis. Crit Care 2011, 15:103. 
34. Kroll MH, Hellums JD, Mclntire LV, Schafer Al, Moake JL: Platelets and shear stress. Blood 1996, 88:1525-1541.

35. Peters MJ, Dixon G, Kotowicz KT, Hatch DJ, Heyderman RS, Klein NJ: Circulating platelet-neutrophil complexes represent a subpopulation of activated neutrophils primed for adhesion, phagocytosis and intracellular killing. Br J Haematol 1999, 106:391-399.

36. Kornerup KN, Salmon GP, Pitchford SC, Liu WL, Page CP: Circulating platelet-neutrophil complexes are important for subsequent neutrophil activation and migration. J Appl Physiol 2010, 109:758-767.

37. Waugh DJ, Wilson C: The interleukin-8 pathway in cancer. Clin Cancer Res 2008, 14:6735-6741.

38. Batal I, Zeevi A, Heider A, Girnita A, Basu A, Tan H, Shapiro R, Randhawa P: Measurements of global cell-mediated immunity in renal transplant recipients with BK virus reactivation. Am J Clin Pathol 2008, 129:587-591.

39. Kowalski R, Post D, Schneider MC, Britz J, Thomas J, Deierhoi M, Lobashevsky A, Redfield R, Schweitzer E, Heredia A, Reardon E, Davis C, Bentlejewski C, Fung J, Shapiro R, Zeevi A: Immune cell function testing: an adjunct to therapeutic drug monitoring in transplant management. Clin Tranplant 2003, 17:77-88.

40. Kumar P, Satchidanandam V: Ethyleneglycol-bis-(beta-aminoethylether) tetraacetate as a blood anticoagulant: preservation of antigenpresenting cell function and antigen-specific proliferative response of peripheral blood mononuclear cells from stored blood. Clin Diagn Lab Immunol 2000, 7:578-583.

41. Ding $F$, Song JH, Jung JY, Lou L, Wang $M$, Charles L, Westover A, Smith PL, Pino CJ, Buffington DA, Humes HD: A biomimetic membrane device that modulates the excessive inflammatory response to sepsis. PLoS One 2011, 6:e18584.

42. Hoesel LM, Neff TA, Neff SB, Younger JG, Olle EW, Gao H, Pianko MJ, Bernacki KD, Sarma JV, Ward PA: Harmful and protective roles of neutrophils in sepsis. Shock 2005, 24:40-47.

43. Karzai W, Cui X, Heinicke N, Niemann C, Gerstenberger EP, Correa R, Banks S, Mehlhorn B, Bloos F, Reinhart K, Eichacker PQ: Neutrophil stimulation with granulocyte colony-stimulating factor worsens ventilator-induced lung injury and mortality in rats. Anesthesiology 2005, 103:996-1005.

44. Scholz M, Cinatl J, Schädel-Höpfner M, Windolf J: Neutrophils and the blood-brain barrier dysfunction after trauma. Med Res Rev 2007, 27:401-416.

45. Humes HD, Sobota JT, Ding F, Song JH, RAD Investigator Group: A selective cytopheretic inhibitory device to treat the immunological dysregulation of acute and chronic renal failure. Blood Purif 2010, 29:183-190.

doi:10.1186/cc12587

Cite this article as: Rimmelé et al: Leukocyte capture and modulation of cell-mediated immunity during human sepsis: an ex vivo study. Critical Care 2013 17:R59.

\section{Submit your next manuscript to BioMed Central and take full advantage of:}

- Convenient online submission

- Thorough peer review

- No space constraints or color figure charges

- Immediate publication on acceptance

- Inclusion in PubMed, CAS, Scopus and Google Scholar

- Research which is freely available for redistribution 